\title{
Analysis on the Construction of Chinese Minority Language and Literature Major Based on the Background of "Double First-class"
}

\author{
Min Gong \\ Northwest Minzu University, Lanzhou 730030, Gansu, China
}

\begin{abstract}
Higher education has achieved unprecedented development in recent years, and the country is paying more and more attention to the development direction of higher education. The construction of "double first-class" is an important strategy for implementing the strategy of strengthening the country with talents. Building a number of key or characteristic colleges and majors into world-class standards will play a huge role in revitalizing the nation and enhancing the overall national strength. The introduction of "double first-class" has allowed many universities and majors to re-examine their future development directions. As a major with local ethnic characteristics, the Chinese Minority Language and Literature major also needs more accurate positioning and planning for its construction. This article will elaborate on the opportunities and challenges faced by the minority language and literature major under the background of "double first-class", the ideas for professional development and construction, and the significance of developing the major, and analyze the construction of the Chinese minority language and literature major.
\end{abstract}

Keywords: "Double first-class", Minority language and literature major, Construction.

1. Opportunities and Challenges for the Minority Language and Literature Major under the Background of "Double First-class"

Minority language and literature major is an indispensable subject in China's contemporary college education. It has long provided high-quality professional talents for minority areas and related enterprises. At the same time, the minority language and literature major also has certain limitations and particularities. Its subject content is mainly aimed at ethnic minority areas. Therefore, under the background of "double first-class" advocated by the state, the development of minority language and literature profession faces a series of opportunities and challenges.

\subsection{Opportunities}

First, the "double first-class" has realized the separation of schools and disciplines. Disciplines no longer rely on the overall identity of the school, and there is more room for independent development. On this basis, the construction of the minority language and literature major is no longer restricted by the comprehensive ranking level of the school, and a path suitable for the development of the discipline can be found on the basis of highlighting the advantages and characteristics of the discipline. Secondly, "double first-class" is a higher education development plan jointly launched by the Ministry of Finance, the Ministry of Education and the National Development and Reform Commission to provide certain financial support for the construction of first-class universities and first-class disciplines. Minority language and literature majors can also benefit from the "double first-class", build a better teaching environment, introduce more professionals, and create a better teaching experience, so as to realize the leap-forward development of minority language and literature majors. Third, "double first-class" will bring a fairer and more open academic competition environment, which is a rare opportunity for minority language and literature majors. On the basis of the continuous improvement of its own academic research and professional training, the minority language and literature major also has the opportunity to stand out and reach a higher level, opening up a new space for the development of the minority language and literature major.

\subsection{Challenges}

In addition to bringing new development opportunities to the minority language and literature major, the "double first-class" education program also gives it more severe challenges. First of all, the "double first-class" plan is to upgrade some universities and majors to world-class levels in a planned way. This process will inevitably lead to the concentration of educational resources. The state takes some key colleges and disciplines as training targets, and will invest more funds and resources to build these colleges and disciplines into a world-class level. At the same time, it will be difficult for some colleges and disciplines to obtain sufficient investment in development and construction. The minority language and literature major is a relatively unpopular major, and it is difficult to obtain educational resources on par with popular majors, which may cause a lag in the development of disciplines. Secondly, "double first-class" will inevitably bring about fierce competition among disciplines of higher education institutions, which will result in the polarization of universities and majors. The advantage of the minority language and literature major in the competition is not outstanding, the chance of standing out is small, and there is the possibility of being more marginalized. Therefore, the competition brought about by "double first-class" will be a huge challenge. 


\section{Thoughts on the Development and Construction of Minority Language and Literature under the Background of "Double First-class"}

In the context of "double first-class", although the minority language and literature major faces many challenges, the various opportunities that exist cannot be ignored. Under the premise of the "double first-class" situation, the minority language and literature major can also create a unique development path as long as it does a good job in self-improvement and construction.

\subsection{Take the Path of Specialized Professional Development}

As a specialized discipline with ethnic minority cultural characteristics, the major of minority languages and literature has irreplaceable advantages. In the future disciplinary construction, the minority language and literature major should blaze a path of specialty development that suits its own development. The minority language and literature major has distinct regional characteristics, mainly for the development of various undertakings in minority areas. In the construction of the minority language and literature major, it is necessary to focus on the cultivation of professional talents, so that students can be proficient in professional skills, that is, minority languages, and enhance the content of the subject with professional strength. While paying attention to the minority language major, the minority language and literature major also needs to take into account the new cultural knowledge that constantly appears in the process of social development, adhere to the principle of advancing with the times, continuously optimize the characteristic teaching structure, update relevant advanced cultural knowledge education, construct a complete professional knowledge and social knowledge system, and create a minority language and literature major with equal emphasis on characteristic majors and comprehensive strength in the new era.

\subsection{Improve the Academic Level of Professional Scientific Research}

The academic level of scientific research is always an important criterion for measuring a profession. If the minority language and literature major is to be unique in the "double first-class" era, it must improve its professional scientific research level. There are many topics related to culture, history, economy, politics, etc. in ethnic minority areas. These topics are related to the economic development of ethnic minority areas, the implementation of the state's regional policies for ethnic minorities, and the investigation of ethnic minority culture and history. Minority language and literature majors should form a professional scientific research team with rich professional knowledge and excellent quality to conduct in-depth research on topics such as the history and culture of ethnic minorities, as well as the comparison of ethnic minority cultures with other ethnic cultures in the world, and create socially valuable Scientific research results, strengthen the professional level construction of disciplines, enhance the gold content of disciplines, and build the hard power of scientific research in minority language and literature majors.

\subsection{Train High-quality Professionals}

The important goal of college majors is to deliver high-quality and high-level professionals to the society. This is also the key to discipline construction. Only by cultivating talents that meet the needs of society can the long-term sustainable development of the discipline be realized. Under the background of "double first-class" fierce competition, the minority language and literature major must first grasp the key to cultivating talents, put people first, and provide students with a better learning and promotion environment. First of all, we must try our best to build good hardware and software facilities for students. Increase the investment in experimental and practical course equipment that has a greater impact on improving professional abilities, and create more comprehensive and convenient learning conditions for students. At the same time, a high-level faculty is needed. The improvement of students' professional ability is closely related to the teaching level of teachers. Therefore, professional construction must not ignore the investment in teachers. Secondly, professional construction also needs to continuously promote the reform of teaching classrooms, explore classroom teaching models that are more in line with the characteristics of the times and professions, create more learning opportunities for students to participate in practice, and enhance students' professional application ability. In addition, it is necessary to strictly manage the students' performance, comprehensively assess the students' professional knowledge mastery and professional application ability, and ensure that students become high-quality professionals after graduation.

\subsection{Face Social Needs}

The training of talents in colleges and universities will eventually go to society and become a part of social construction. Therefore, in the direction of talent training, colleges and universities must first consider the needs of society. The minority language and literature major is a special subject, and its scope of employment is not as wide as that of other popular subjects. Therefore, in the training of professional talents, special consideration should be given to the society's demand for relevant talents. At present, judging from the employment situation of past graduates, the demand for ethnic minority language and literature majors is mainly in the ethnic minority areas to which they belong. Some ethnic minority-related government departments, enterprises and institutions are still the main receiving units of graduates. These units not only require Master the minority languages, as well as the knowledge of minority culture and history, excellent news writing ability, literary creation ability, and practical application ability in a modern social media environment. This requires more work internships to be carried out in the construction of ethnic minorities' majors, to enhance the comprehensive capabilities required by 
employers, and to better meet the requirements of social work for talents.

\section{The Significance of Developing Minority Language and Literature under the Background of "Double First-class"}

The introduction of the "double first-class" policy will stimulate the development of minority language and literature majors, expand the team of minority language and literature talents, and improve the quality of minority language and literature talents, thereby further promoting the economic development of ethnic minority areas and the inheritance of traditional excellent culture. And maintained the state of national unity.

\subsection{Promote the Coordinated Development of Ethnic Minority Regions and other Regions}

China's regional development is extremely uneven, especially in ethnic minority areas, which still face many livelihood issues such as poverty and backwardness. Ethnic minority areas have always been part of the overall national development and part of the motherland's big family, and they are also burdened with achieving common prosperity. The goal. In order to develop the economy of ethnic minority areas, we must first improve the local cultural level, which requires a large number of talents proficient in ethnic minority culture to participate in the construction, and the minority language and literature major is the cradle of cultivating relevant talents. The input of ethnic minority language and literature talents has brought contemporary advanced ideology and culture. At the same time, they are familiar with local culture and customs, which can more smoothly lead ethnic minority areas out of the inherent thinking shackles and development difficulties, find a path suitable for local development, and promote the local economy growth and progress will narrow the gap with developed regions and achieve coordinated and common development with other regions.

\subsection{Inherit and Develop the Excellent Culture of Ethnic Minorities}

Minority culture is a treasure of our traditional culture. With the advent of globalization, culture is becoming more and more homogenized. More and more indigenous people of ethnic minorities are leaving their homes and divorced from the original cultural context. Traditional culture of ethnic minorities Facing the danger of extinction, protecting and inheriting the culture of ethnic minorities has become an important task of the times. The major of minority languages and literature mainly trains talents with knowledge of minority languages and culture, and inherits and spreads the traditional culture of minority peoples by means of higher education. After entering the society, ethnic minority language and literature talents will continue to deepen their connection with ethnic minority culture and promote the development of ethnic minority culture by participating in ethnic minorities' related work.

\subsection{Maintain National Unity}

China is a multi-ethnic country. The big family of fifty-six ethnic groups has a wide variety of ethnic cultural traditions. If the fifty-six ethnic groups are to unite as one, we must deepen our understanding of ethnic culture and achieve mutual understanding and tolerance. The future work of the talents trained in the minority language and literature major is to establish cultural communication links, bring mainstream culture into ethnic minority areas, and at the same time promote ethnic minority culture, or allow ethnic minorities to have more communication and dialogue with the outside world. The aim is to establish a sense of identity between nations, promote the unity and friendship between different nations, and ensure the stable development of the country.

\section{References}

[1] Ou Yike. Construction and Development of Chinese Minority Language and Literature Discipline Group-Taking Guangxi University for Nationalities as an example [J]. Journal of Guangxi University for Nationalities, 2009, 31 (01): 181-184.

[2] Zhou Yongxiong. Analysis of Professional Culture Construction under the Background of "Double First-class" [J]. Journal of Tongren University, 2017 (07): 62-66

[3] Huang Li. Research on the Ways of Specialty Construction under the Background of "double first-class" [J]. Journal of Kaifeng Institute of Education, 2019, 39 (02): 120-121.

[4] Qu Mu Tiexi. The Goal and Path of the Construction of the Ethnic Language and Literature Major in Colleges and Universities under the Background of "Double First-class" [J]. National Education Research, 2020, 31 (03): 54-60. 